\title{
Functional panchromatic BODIPY dyes with near-infrared absorption: design, synthesis, characterization and use in dye-sensitized solar cells
}

\author{
Quentin Huaulmé $^{1}$, Cyril Aumaitre ${ }^{1}$, Outi Vilhelmiina Kontkanen², David Beljonne ${ }^{2}$, \\ Alexandra Sutter ${ }^{3}$, Gilles Ulrich ${ }^{3}$, Renaud Demadrille ${ }^{* 1}$ and Nicolas Leclerc ${ }^{* 3}$
}

\author{
Full Research Paper \\ Address: \\ ${ }^{1}$ CEA, Univ. Grenoble Alpes, CNRS, IRIG, SyMMES, F-38000 \\ Grenoble, France, ${ }^{2}$ Chimie des Matériaux Nouveaux \& Centre \\ d'Innovation et de Recherche en Matériaux Polymères Université de \\ Mons - UMONS / Materia Nova Place du Parc, 20, B-7000 Mons, \\ Belgium and ${ }^{3} \mathrm{ICPEES}$ - UMR7515, CNRS-Université de Strasbourg, \\ 25 rue Becquerel, 67087 Strasbourg CEDEX 02, France \\ Email: \\ Renaud Demadrille* - renaud.demadrille@cea.fr; Nicolas Leclerc* - \\ leclercn@unistra.fr \\ ${ }^{*}$ Corresponding author \\ Keywords: \\ boron-dipyrromethene; BODIPY; dye-sensitized solar cells; \\ near-infrared absorbers; organic dyes
}

\author{
Beilstein J. Org. Chem. 2019, 15, 1758-1768. \\ doi:10.3762/bjoc.15.169
}

Received: 12 April 2019

Accepted: 10 July 2019

Published: 24 July 2019

This article is part of the thematic issue "Dyes in modern organic chemistry".

Guest Editor: H. Ihmels

(c) 2019 Huaulmé et al.; licensee Beilstein-Institut.

License and terms: see end of document.

\begin{abstract}
We report two novel functional dyes based on a boron-dipyrromethene (BODIPY) core displaying a panchromatic absorption with an extension to the near-infrared (NIR) range. An innovative synthetic approach for preparing the 2,3,5,6-tetramethyl-BODIPY unit is disclosed, and a versatile way to further functionalize this unit has been developed. The optoelectronic properties of the two dyes were computed by density functional theory modelling (DFT) and characterized through UV-vis spectroscopy and cyclic voltammetry (CV) measurements. Finally, we report preliminary results obtained using these functional dyes as photosensitizers in dyesensitized solar cells (DSSCs).
\end{abstract}

\section{Introduction}

The past two decades have witnessed tremendous efforts to develop alternative photovoltaic (PV) technologies. Among them, dye-sensitized solar cells (DSSCs) display numerous advantages compared to its fully organic counterpart, i.e., bulk heterojunction solar cells, or other hybrid PV technologies such as perovskite solar cells. DSSCs can display satisfactory power conversion efficiencies (PCE) in the range of 10 to $14 \%$ [1-3] but also a long-term stability when specific electrolytes based on ionic liquids are employed [4,5]. Besides, this technology enables the fabrication of solar panels that can be prepared 
semi-transparent, colorful, and out of non-toxic constituents [6]. Historically, Ru(II)-polypyridyl complexes were the most used dyes as photosensitizers in DSSCs (N719 or N749 Black Dye) [7] but these molecules reveal low absorption coefficients over the visible range. Furthermore, they contain a rare and a relatively high-cost element $(\mathrm{Ru})$ and their plausible toxicity restrains their development at the industrial level. For these reasons, in the last decade, metal-free organic dyes based on donor-( $\pi$-spacer)-acceptor structure have hence been extensively investigated and screened as sensitizers in DSSCs. Among the hundreds of dyes developed so far for this application, only few can show panchromatic absorption [8,9]. To improve the photogeneration of current, and hence the efficiency of DSSCs, the development of new dye molecules better matching the solar emission spectrum or exhibiting absorption in the near-infrared (NIR) range could be a fruitful strategy.

Several families of molecules displaying an infrared absorption have been investigated in the last decade, such as phthalocyanines [10,11], organic push-pull compounds [12], and boron-dipyrromethene [13] (BODIPY ${ }^{\circledR}$ ). BODIPY dyes are one of the most extensively studied class of fluorophores due to their unique properties, including high absorption coefficients in the visible and NIR ranges, high fluorescence quantum yields, and high stability in various media. More importantly, they display a very versatile chemistry, allowing the fine tuning of all their physical and optical properties [14]. They hence have found applications in various fields, such as lasers dyes [15], (bio)-labeling [16,17], photodynamic therapy [18], or even bulk heterojunction solar cells $[19,20]$ or DSSCs [21,22].

In this articl we report an innovative synthetic approach for synthesizing 2,3,5,6-tetramethyl-BODIPY compounds and a way to further functionalize such cores has been developed. The optoelectronic properties of the functional molecules were investigated using UV-vis spectroscopy, and we show that they can absorb light up to $900 \mathrm{~nm}$ in solution and $1000 \mathrm{~nm}$ in solid state, after grafting on anatase- $\mathrm{TiO}_{2}$ mesoporous films. The cyclic voltammetry (CV) measurements indicate that the compounds have HOMO and LUMO energy levels suitable for an application in DSSCs, in rather good agreement with the values obtained from DFT calculations. Finally, we report preliminary results employing these molecules as photosensitizers in dye solar cells with iodine-based liquid electrolytes. We show that the limited performances of these new BODIPY derivatives arise from their deep LUMO energy level. In terms of energy, the latter lies close to the conduction band of the electron-transporting oxide, limiting therefore the driving force of electronic injection, and hence the overall efficiency of the resulting solar cell.

\section{Results and Discussion \\ 1. Design and DFT calculations}

In many opto-electronic devices the light-absorption properties of the semiconductors are a critical parameter. This is particularly the case when solar energy conversion applications are targeted. For instance, in order to maximize the photocurrent density in a DSSC device, the sensitizer has to display high molar absorption coefficients, ideally along the entire visible range. Additionally, it must display appropriate positioning of frontier molecular orbitals (highest occupied molecular orbital/ lowest unoccupied molecular orbital, HOMO/LUMO) energy levels with respect to the conduction band (CB) of the metal oxide and the redox potential of the electrolyte. Abundant literature on BODIPY derivatives allowed us to identify a chemical approach to fulfill those criteria, i.e., the introduction of an electron rich unit at the 3rd and 5th positions of the BODIPY core via a vinyl spacer $[14,21,23,24]$. Introduction of such units on those positions is known to lead to a larger bathochromic shift of the $\mathrm{S}_{0} \rightarrow \mathrm{S}_{1}$ absorption band than the same substitution on its 2nd and 6th positions [25]. A thiophene-triphenylamine unit was selected among the reported electron-donating units, due to its reversible redox properties and high electron-donating strength (see Figure 1) [26]. In order to promote the delocalization from the electron-donating unit to the electron-withdrawing and anchoring group located on its 8 position, a 2,3,5,6-tetramethyl-BODIPY derivative has been designed (see Figure 1). Indeed, most of the BODIPY based materials, used in organic semiconducting applications, exhibit methyl groups in the 1,7-positions. However, such groups in these positions hinder sterically the position 8 of BODIPY cores and therefore lead to a severe twist of the aromatic unit grafted on. Removing these methyl groups is an effective way to reduce the dihedral angle between the meso substituent and the BODIPY core by lowering the steric hindrance between the two latter. It has been previously reported that a better molecular planarity usually originates a higher charge injection efficiency [27]. Furthermore, it has been reported that introduction of hydrophobic alkyl chains on a sensitizer is a way to improve the open-circuit voltage $\left(\mathrm{V}_{\mathrm{oc}}\right)$, by reducing the electronic recombination rate at the electrolyte/semi-conducting oxide interface [28]. To probe the validity of this concept for a BODIPY derivative, we decided to synthetize the two molecular structures disclosed in Figure 1, namely BOD-TTPA-alk and BODTTPA.

To support our molecular design, and especially to have better insight on the electronic structure and optical properties of the dyes, we performed (time-dependent) density functional theory (TD-DFT) calculations on the four representative molecules displayed in Figure 2: Dyes (1 and 3) vs ( 2 and 4) differ by the position $(2,6$ or 1,7$)$ of the methyl groups on the BODIPY core, 


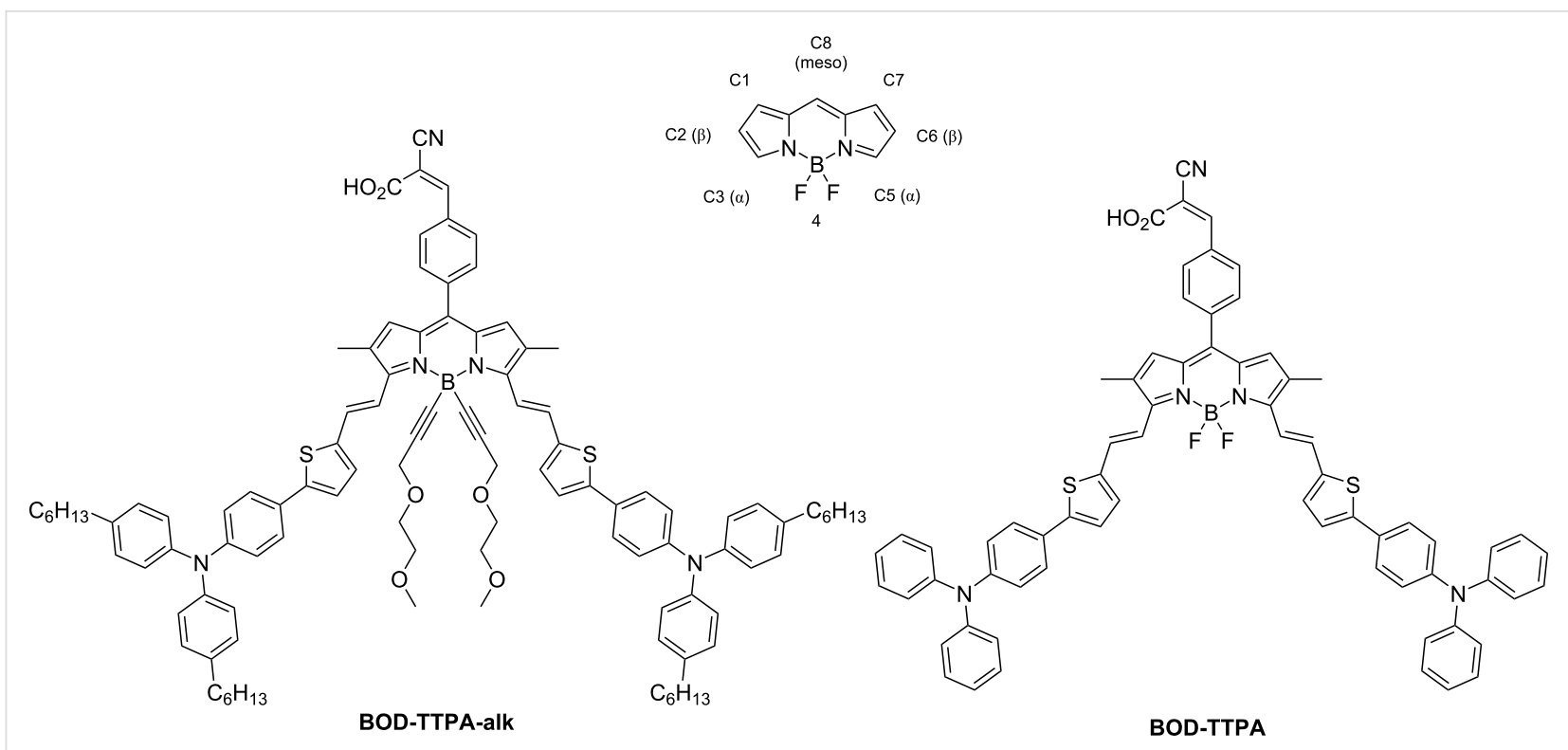

Figure 1: Molecular structures of the two target compounds BOD-TTPA-alk and BOD-TTPA, and the chemical structure of a BODIPY core displaying its positions numbering.

while dyes (1 and $\mathbf{2}$ ) vs ( $\mathbf{3}$ and $\mathbf{4})$ differ by the presence (or not) of a triphenylamine donor group on the thiophene ring. As we are dealing with charge-transfer electronic excitations, we have adopted a tuned range-separated CAM-B3LYP functional and the polarizable continuum model (PCM) to account for (implicit) solvent effects (in THF).

The one-electron energy diagram reported in Figure 2 shows that: (i) Grafting the triphenylamine donor moieties on the thiophene-vinylene bridge only slightly (by ca. $0.1 \mathrm{eV}$ ) lowers the ionization potential of the dyes, compare $(\mathbf{1 , 2})$ to $(\mathbf{3 , 4})$; this is explained by the fact that the HOMO molecular orbital mostly spreads on the BODIPY-vinylthiophene core of the molecules, with only slight contributions from the TPA units (ii) The position of the methyl groups has by far a larger impact on the electron affinity of the molecules, which is substantially increased when going from $\mathbf{2}$ to $\mathbf{1}$, and from $\mathbf{4}$ to $\mathbf{3}$. This is clearly not a direct electronic effect but rather results from the close to orthogonal orientation of the anchoring groups induced by steric effects in $\mathbf{2}$ and $\mathbf{4}$. As a result, while the LUMO orbital largely extends through the BODIPY unit towards the cyanoacrylic acid anchors in the case of $\mathbf{1}$ and $\mathbf{3}$, it is completely confined to the BODIPY-vinylthiophene core in $\mathbf{2}$ and $\mathbf{4}$, explaining the deeper unoccupied levels in the former molecules.

Thus, our calculations suggest that, in case of an allowed HOMO-LUMO transition, $\mathbf{1}$ and $\mathbf{3}$ should show a bathochromically shifted optical absorption spectrum, thereby hopefully allowing for a more efficient sunlight absorption, yet also a reduced energy driving force for charge separation at the $\mathrm{TiO}_{2}$ surface. To check this hypothesis, we performed TD-DFT simulations of the optical absorption spectra of the 4 representative dyes. The results reported in Figure 3 are fully consistent with the predictions from the one-electron picture. There is a substantial red shift of the lowest optical absorption band, from $\approx 750 \mathrm{~nm}$ in $\mathbf{2}$ to $\approx 850 \mathrm{~nm}$ in $\mathbf{1}$ by moving the methyl groups from $(1,7)$ to $(2,6)$ positions, in line with the increased electronic delocalization over the anchoring groups. An additional virtue of the placement of the methyl groups in positions $(2,6)$ is to extend the absorption range of the dyes across the whole visible range. Very similar effects are observed for the TPAfree molecules, except for an overall blue shift of the main absorption bands resulting from the reduced size of the $\pi$-electronic system.

\section{Synthesis}

The synthesis of the target materials is schemed in Figure 4. To introduce the selected substitution pattern, 2,3-dimethylpyrrole $\mathbf{1}$ is first synthesized through a Trofimov reaction in a one-pot two-step reaction [29]. The condensation of the aforementioned pyrrole on para-iodobenzoyl chloride affords the corresponding dipyrromethenium chloride, which was then converted into its BODIPY analogue 2 through complexation by $\mathrm{BF}_{3} \cdot \mathrm{OEt}_{2}$ in basic media. Regioselective introduction of distyryl substituents is achieved via Knoevenagel-type condensation in the presence of piperidine using aldehyde derivatives 3 and $\mathbf{4}$ whose synthesis are described in Supporting Information File 1. This condensation reaction affords compounds $\mathbf{5}$ and $\mathbf{6}$ with a slight variation of their pendant alkyl chains. The stereoisomerism of 


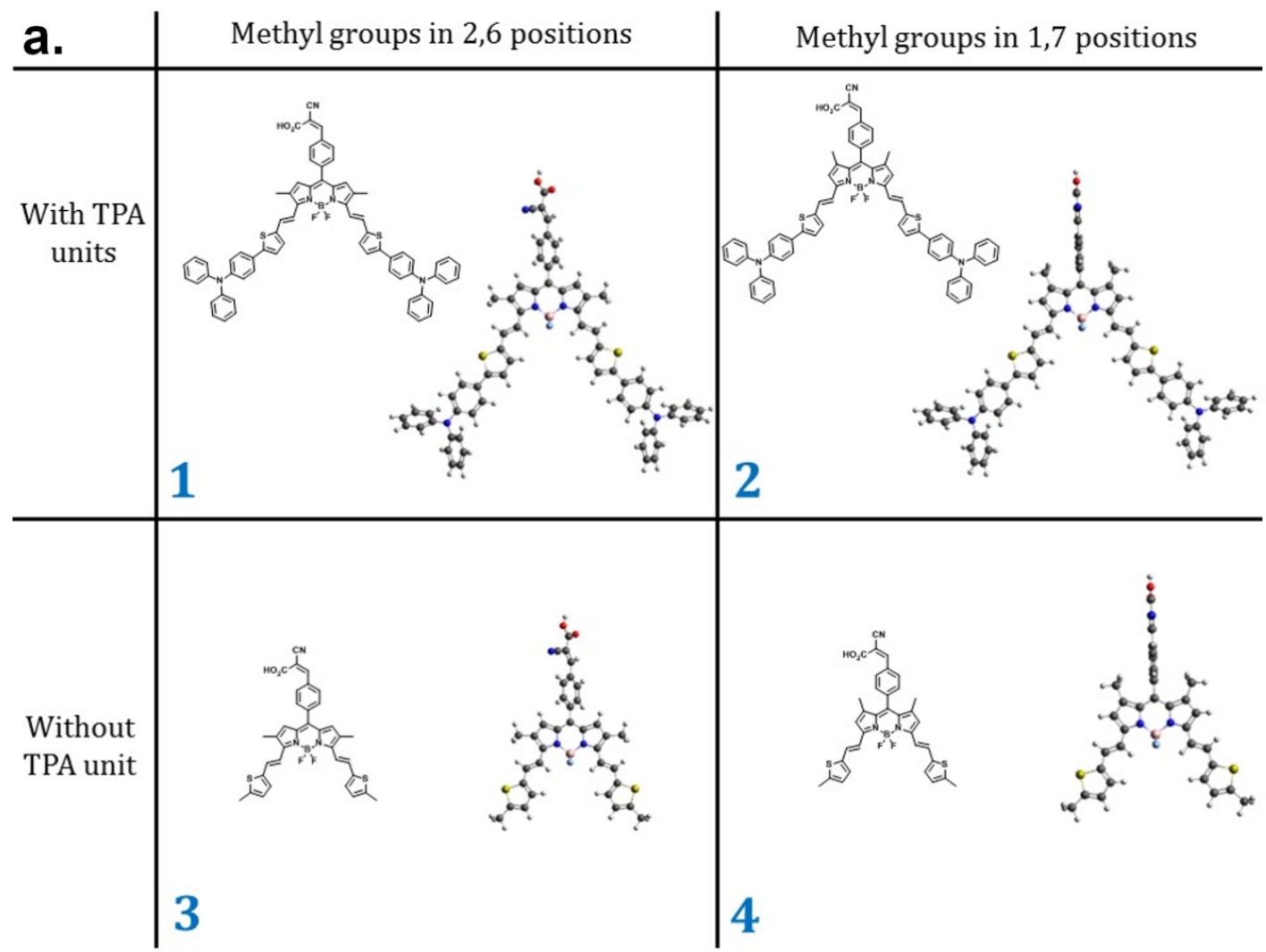

\section{b. Energy (eV)}
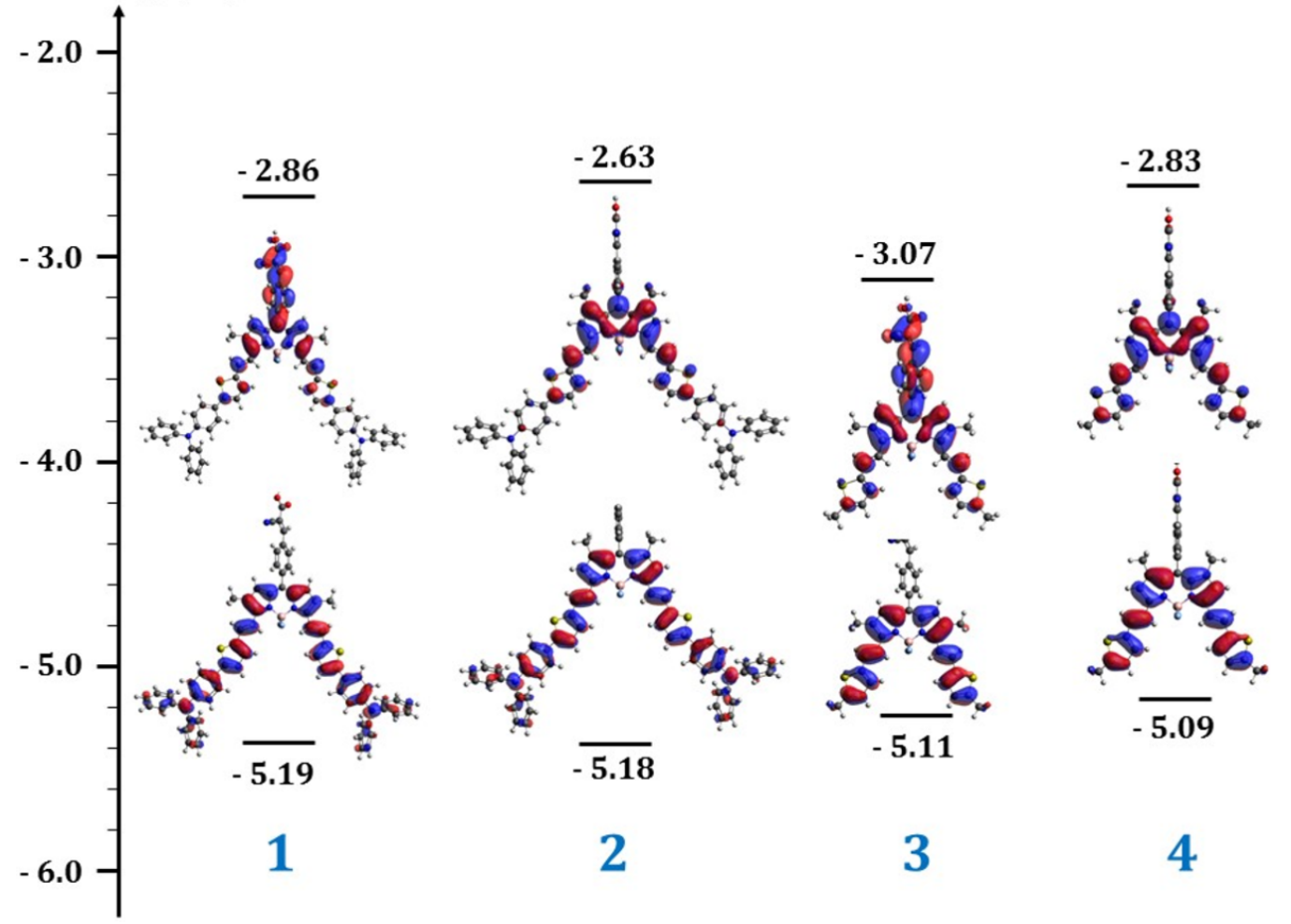

Figure 2: a) Geometrical optimization of four representative BODIPY-based materials for DSSCs application. b) Frontiers molecular orbitals repartition and their predicted energy values for the selected four representative BODIPY-based dyes. 


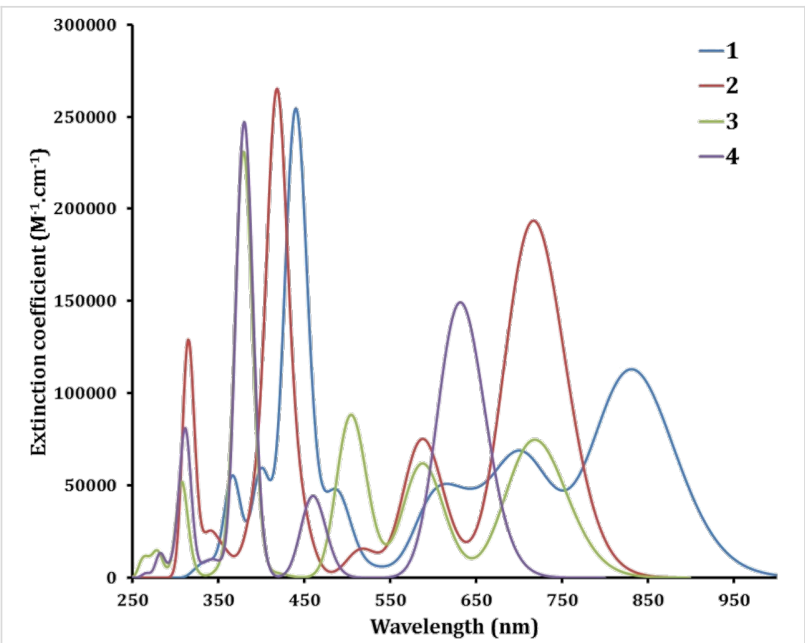

Figure 3: Predicted absorption spectra of the four dyes. the resulting distyryl compound (trans) has been unambiguously attributed by ${ }^{1} \mathrm{H}$ NMR (see Figures S9 and S11 in Supporting Information File 1), whose spectra feature characteristic constant couplings of 16.2 and $16.1 \mathrm{~Hz}$. It is worth mentioning that the fluorine substitution was performed on the boron center after introduction of the styryl residues, introduction prior to the Knoevenagel reaction is known to impede it [30]. The introduction of the aldehyde moiety is carried out through catalytic carbo-palladation reaction using molecular carbon monoxide in the presence of methyl formiate as hydrogen source in modest yield (35\% and 19\% for $\mathbf{8}$ and 10, respectively) due to the formation of a relatively large amount of dehalogenation side-product. Finally, a Knoevenagel condensation in the presence of cyanoacetic acid and piperidine is performed to lead to the targeted compounds BOD-TTPA-alk and BODTTPA.

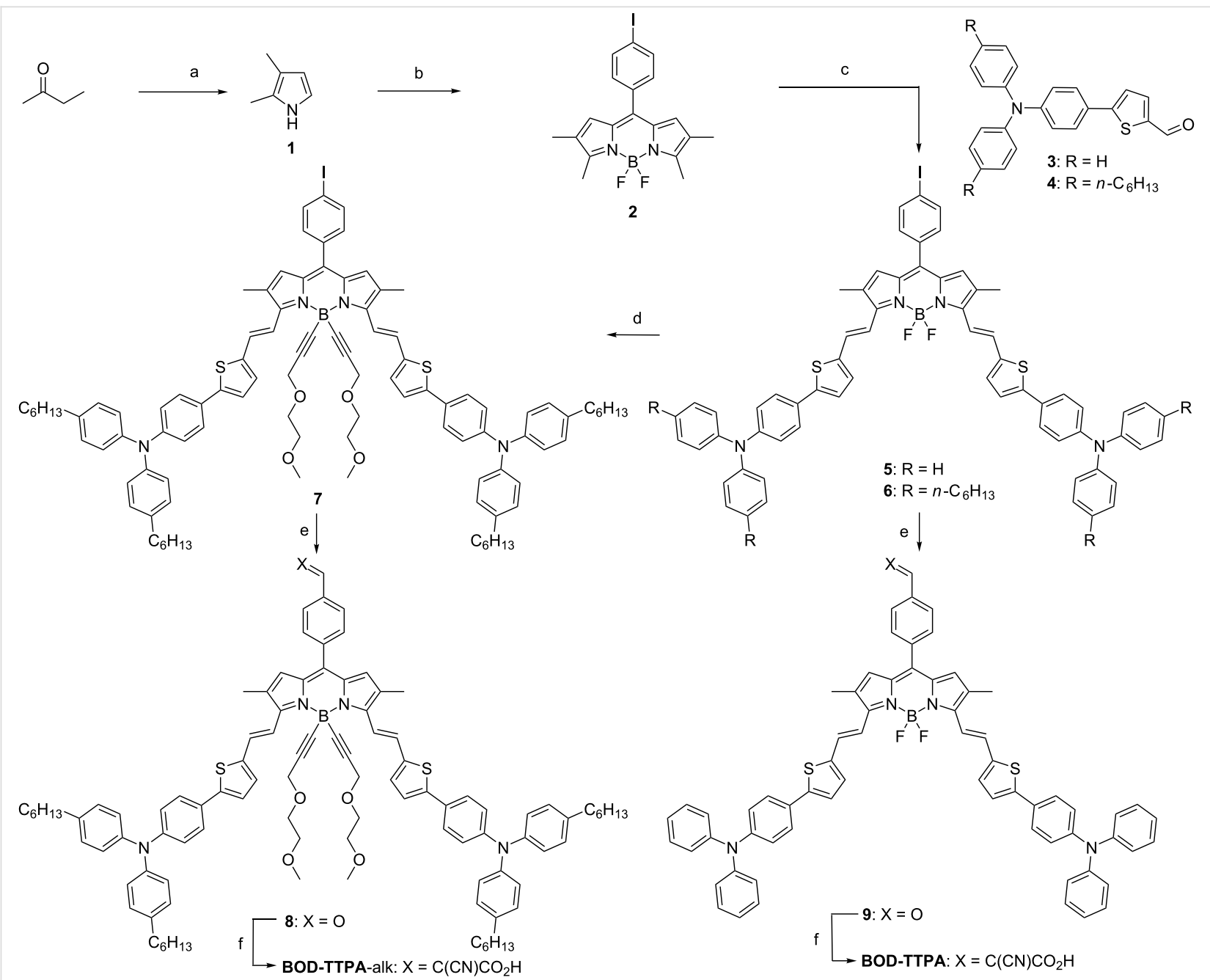

Figure 4: Synthetic scheme of the selected materials. a) hydroxylamine hydrochloride, $\mathrm{NaHCO}_{3}, \mathrm{DMSO}, 60{ }^{\circ} \mathrm{C}$ then acetylene, $\mathrm{KOH}, \mathrm{DMSO}, 110$ ${ }^{\circ} \mathrm{C}, 24 \%$ over the two steps; b) 4-iodobenzoyl chloride, DCM, rt then DDQ, DCM, rt then $\mathrm{NEt}_{3}, \mathrm{BF}_{3} \cdot \mathrm{OEt}_{2}, 0{ }^{\circ} \mathrm{C}$ to rt, $35 \%$; c) piperidine, cat. PTSA, toluene, $130{ }^{\circ} \mathrm{C}, 5: 35 \%, 6: 30 \%$; d) (3-(2-methoxyethoxy)prop-1-yn-1-yl)magnesium bromide, THF, $60{ }^{\circ} \mathrm{C}, 85 \%$; e) carbon monoxide, sodium formiate, $\left[\mathrm{Pd}\left(\mathrm{PPh}_{3}\right)_{2} \mathrm{Cl}_{2}\right.$ ], anhydrous DMF, $100{ }^{\circ} \mathrm{C}, \mathbf{8}$ : $19 \%, 9: 35 \%$; f) cyanoacetic acid, piperidine, $\mathrm{MeCN} \mathrm{CHCl}_{3}, 80{ }^{\circ} \mathrm{C}, \mathrm{BOD}-\mathrm{TTPA}: 34 \%$, BODTTPA-alk: $26 \%$. 


\section{Optical properties}

The optical properties of compounds BOD-TTPA-alk and BOD-TTPA were first evaluated in diluted $\left(\approx 10^{-6} \mathrm{M}\right.$ in THF) solution (see Figure 5). They both display two intense absorption bands. At lower energy, the absorption band displays a rather large and high extinction coefficient $\left(5 \cdot 10^{-4} \mathrm{M}^{-1} \mathrm{~cm}^{-1}\right)$ band attributed to the $S_{0} \rightarrow S_{1}$ transition of the BODIPY core, and still displays its characteristic shoulder at higher energy [14]. Another intense absorption band is located around $400 \mathrm{~nm}$ and is attributed to the $\pi \rightarrow \pi^{*}$ transition of the triphenylamine thiophene residues. It is worth noting that almost no difference is observed between those two materials, which is consistent with their identical electronic structure. As often with such distyryl-BODIPY derivatives [19,25], no clear cut-off of absorbance is observed in the whole part of the visible range, leading to a panchromatic absorption. The absorption is not limited to the visible domain, indeed the compound BOD-TTPA-alk and BOD-TTPA exhibit a $\lambda_{\max }$ in solution located at $771 \mathrm{~nm}$ and $768 \mathrm{~nm}$, respectively, with an absorption edge close to
$900 \mathrm{~nm}$. The absorption in the NIR region is a peculiar property that is of course a considerable advantage for solar cell applications.

With the aim of investigating the behavior of those dyes once adsorbed on mesoporous $\mathrm{TiO}_{2}$, sensitization has been performed on $2 \mu \mathrm{m}$ thick $\mathrm{TiO}_{2}$ mesoporous layer (see Figure $5 \mathrm{~b}$ and c). To prevent dye aggregation on the surface of the semiconducting oxide, and to mimic the real conditions of use in solar cells, chenodeoxycholic acid (CDCA) was employed as co-sensitizer and hence added to the sensitization solution [31]. For the dyeing solutions the concentration of the dye was $1 \mathrm{mM}$ and the concentration of CDCA was $10 \mathrm{mM}$ in a chloroform/ ethanol mixture (1:1 in volume). The absorbance spectra of the resulting sensitized $\mathrm{TiO}_{2}$ layers are recorded and presented in Figure $5 b$.

For both dyes, grafting them on the surface clearly impacts the absorption bands attributed to the BODIPY part of the systems.
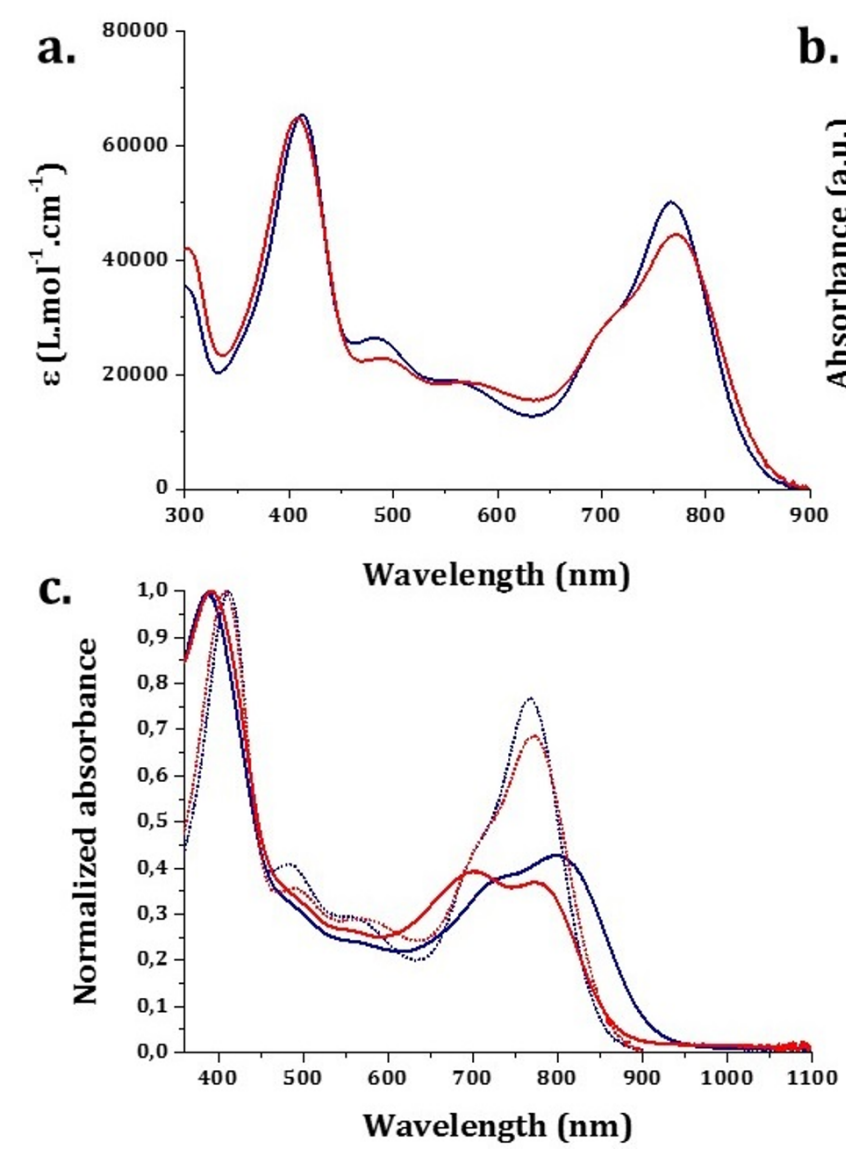

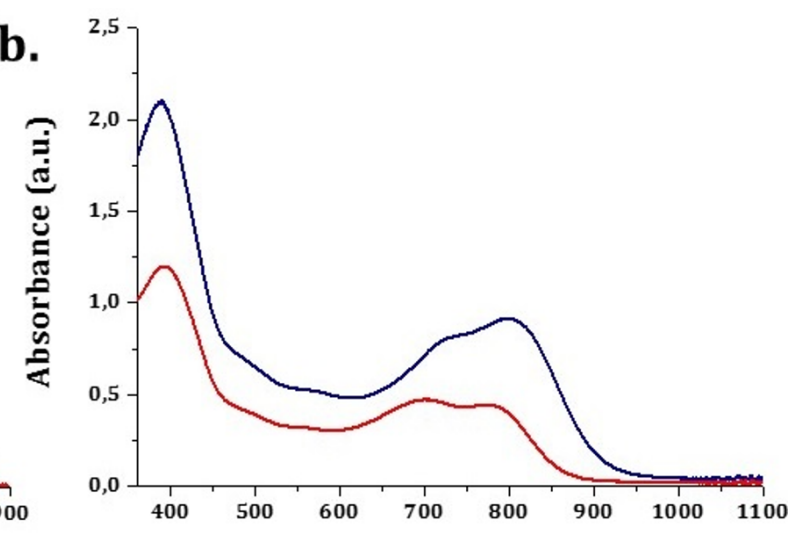

Wavelength (nm)

\section{…. BOD-TTPA-alk}

\section{…. BOD-TTPA}

Figure 5: a) Absorption spectra of compounds BOD-TTPA-alk and BOD-TTPA (THF, $\approx 10^{-6} \mathrm{M}, 25^{\circ} \mathrm{C}$ ). b) Absorbance spectra of $2 \mu \mathrm{m}$ thick mesoporous $\mathrm{TiO}_{2}$ sensitized in a solution of dye/CDCA (1:10, molar ratio). c) Normalized absorbance spectra of BOD-TTPA-alk (red traces) and BODTTPA (blue traces), both in diluted solution (aerated THF, $\approx 10^{-6} \mathrm{M}, 25^{\circ} \mathrm{C}$ - dashed lines) and once adsorbed on $2 \mu \mathrm{m}$ thick mesoporous TiO 2 (solid lines). 
The absorption coefficient of the lower energy absorption band, attributed to the $S_{0} \rightarrow S_{1}$ transition, is reduced and a higher energy band around $700 \mathrm{~nm}$ increases in intensity. This last one is more likely attributed to a conformationally restricted form of the dye once adsorbed which shows an absorption value closed to mono-styryl species, thus reinforcing the panchromatic absorption of this dye. As long as BOD-TTPA-alk is concerned, no significant shift of the lower energy band is observed (see Table 1 and Figure 5a). This suggests no self-aggregation of the alkylated dye occurs on the oxide surface, which can be explained by the presence of the co-adsorbent CDCA, and of the multiple alkyl chain substitution of the TPA units. On the other hand, a bathochromic shift of the absorption profile of BOD-TTPA is observed from diluted solution to the anchored dye (see Figure 5a). Despite the same amount of CDCA in the dyeing solution (10 molar equivalents), this result suggests a higher tendency for $\pi$ stacking interactions. Once anchored, BOD-TTPA exhibits consequently a broader absorption profile than its alkylated counterpart BOD-TTPA-alk.

Furthermore, the measured intensity of absorbance of the sensitized $\mathrm{TiO}_{2}$ layer is much higher for BOD-TPA than BODTTPA-alk in spite of the fact that the dyeing was performed with solutions containing exactly the same concentration of the dyes. The thickness of the aforementioned $\mathrm{TiO}_{2}$ layer being identical and the two dyes BOD-TTPA-alk and BOD-TTPA displaying very similar absorption coefficient (see Table 1), sensitization of mesoporous $\mathrm{TiO}_{2}$ will be more effective for BOD-TTPA than BOD-TTPA-alk. This lower absorption originating from a lower grafting level may arise from the overall size of the molecule BOD-TTPA-alk that displays 4 alkyl chains and 2 ethylene glycol chains. The bigger size of BODTTPA-alk can eventually prevents its diffusion through all the pores of the $\mathrm{TiO}_{2}$ layer or decreases the density of grafted molecules due to steric hindrance.

\section{Electrochemical characterization}

Cyclic voltammetry of both BODIPY dyes was carried out in deoxygenated DCM solutions containing tetrabutylammonium hexafluorophosphate as salt (see Figure S24 and S25 in Supporting Information File 1), to investigate their oxidation and reduction processes as well as to determine the energy levels of their highest occupied molecular orbital (HOMO) and lower unoccupied molecular orbital (LUMO). All the redox potentials were calibrated with respect to Ferrocene $(\mathrm{Fc})$, assuming that $E\left(\mathrm{Fc} / \mathrm{Fc}^{+}\right)=0.40 \mathrm{~V}$ with respect to $\mathrm{SCE}$ (see experimental details). The low solubility of the BOD-TTPA derivative makes this material much more difficult to characterize than its alkylated counterpart. However, both dyes exhibit similar first oxidation potentials about $0.6 \mathrm{~V}$ and $0.55 \mathrm{~V}$ for BOD-TTPA and BOD-TTPA-alk, respectively. Both processes are reversible. It worth noting that the BOD-TTPA-alk exhibits also a second reversible oxidation process at higher voltage of 0.8 V. Finally, for both dyes, a quasi-reversible reduction process could be observed at $-0.6 \mathrm{~V}$ and $-0.8 \mathrm{~V}$ for BOD-TTPA and BOD-TTPAalk, respectively.

The HOMO and LUMO levels were determined by using the following equations $\left(\mathrm{HOMO}=E_{\mathrm{OX}}+4.4 \mathrm{eV}\right)$ and $(\mathrm{LUMO}=$ $E_{\text {red }}+4.4 \mathrm{eV}$ ) where the onset potentials are in volts (vs SCE) and HOMO and LUMO are in electron volts [32]. We thus calculated HOMO and LUMO levels of $-5.0 \mathrm{eV}$ and $-3.8 \mathrm{eV}$ for BOD-TTPA against $-4.95 \mathrm{eV}$ and $-3.6 \mathrm{eV}$ for BODTTPA-alk. The small change of the HOMO energy levels is in line with the performed calculations (see section 1), where the HOMO molecular orbital is shown to be mostly spread on the BODIPY-vinylthiophene moieties of the dyes, with only slight contributions from the TPA units. The significant decrease in electronic affinity observed in BOD-TTPA-alk is likely due to the boron center alkylation. Similar effects have been already shown after fluorine substitution of BODIPY [33].

\section{DSSCs fabrication and device performances}

In order to investigate the photovoltaic performances of the two functional dyes BOD-TTPA-alk and BOD-TTPA, a set of DSSCs were fabricated following a procedure reported previously [4]. The $J(\mathrm{~V})$ characteristics of the devices were recorded in dark and upon irradiation with a mask. For the measurements a solar simulator with AM 1.5G filter was used after calibration with a Silicon cell at $1000 \mathrm{~W} \mathrm{~m}^{-2}$. For a direct comparison, we fabricated solar cells with the same photoelectrode composition consisting of a double layer $\mathrm{TiO}_{2}$ (a $12 \mu \mathrm{m}$-thick transparent layer and a $4 \mu \mathrm{m}$-thick scattering layer) purchased

Table 1: Selected optical properties of compounds BOD-TTPA-alk and BOD-TTPA.

\begin{tabular}{llllll} 
Compounds & $\lambda_{\max }^{\text {solution }}(\mathrm{nm})$ & $\varepsilon\left(\mathrm{L} \cdot \mathrm{mol}^{-1} \cdot \mathrm{cm}^{-1}\right)$ at $\lambda_{\max }^{\text {solution }}$ & $\lambda_{\text {onset }}^{\text {solution }}(\mathrm{nm})$ & $\lambda_{\text {max }}^{\mathrm{TiO}_{2}}(\mathrm{~nm})$ & $\lambda_{\text {onset }}^{\mathrm{TiO}}(\mathrm{cm})$ \\
\hline BOD-TTPA-alk & 409,771 & $6.49 \cdot 10^{4}, 4.46 \cdot 10^{4}$ & 841 & $393,700,771$ \\
BOD-TTPA & 411,768 & $6.52 \cdot 10^{4}, 5.00 \cdot 10^{4}$ & 856 & 389,801
\end{tabular}


from Solaronix. This thickness was selected on the basis of a previous study showing that thicker electrodes (typically above $12 \mu \mathrm{m})$ give rise to highest photocurrent density.

When dyes with low-lying LUMO energy levels are employed as sensitizers together with $\mathrm{TiO}_{2}$ electrodes, the choice of the electrolyte is crucial. From CV experiments (see previous section) we found that the LUMO levels of the dyes are at -3.9 and $-3.6 \mathrm{eV}$. In other words, they are located roughly $0.1-0.4 \mathrm{eV}$ above the energy level of the conducting band of the oxide (which is around $-4 \mathrm{eV}$ ). This alignment of the energy levels could be damaging to the electron injection process. Indeed, it is known that a minimum driving force of $0.15 \mathrm{eV}$ (neglecting entropy changes during the light absorption) is required to efficiently inject photo excited electrons from the LUMO of the dyes in the CB of the oxide [34].

Usually iodine-based liquid electrolytes are comprising additives such as tert-butylpyridine ( ${ }^{\mathrm{t}} \mathrm{BP}$ ) which is known to shift the $\mathrm{CB}$ band of the oxide positively by creating a dipole effect at the surface of $\mathrm{TiO}_{2}$. By suppressing this dipole effect, the $\mathrm{CB}$ of $\mathrm{TiO}_{2}$ could be relocated deeper and this could facilitate the photo-injection process. Consequently, for preliminary investigations we prepared an electrolyte with a formulation close to the one of HI-30 commercialized by Solaronix. HI-30 electrolyte is known to be compatible with a large variety of organic dyes. We therefore designed a modified electrolyte inspired from HI-30 with the following composition: $0.5 \mathrm{M}$ of butylmethylimidazolium iodide (BMII), $0.03 \mathrm{M}^{\text {of } \mathrm{I}_{2}} 0.5 \mathrm{M}$ of LiI, $0.1 \mathrm{M}$ of guanidinium thiocyanate in a mixture of acetonitrile and 3-methoxyproprionitrile (85:15). Compared to classical electrolytes, in this formulation we removed ${ }^{t} \mathrm{BP}$, hoping that the suppression of the interface dipole would shift the $\mathrm{CB}$ energy level of $\mathrm{TiO}_{2}$ and, consequently, enhance injection process [35].

The $J(\mathrm{~V})$ curves of the devices containing compounds BODTTPA-alk and BOD-TTPA are reported in Figure 6. Selected photovoltaic parameters obtained from three different measurements for each dye are gathered in Table 2. BOD-TTPA-alk exhibits a maximum power conversion efficiency of $1.12 \%$ a short-circuit current $\left(J_{\mathrm{sc}}\right)$ of $4.70 \mathrm{~mA} \cdot \mathrm{cm}^{-2}$, an open-circuit voltage $\left(V_{\mathrm{oc}}\right)$ of $0.37 \mathrm{~V}$ and a fill factor $(\mathrm{FF})$ of $65 \%$. On the other hand, BOD-TTPA displays a power conversion efficiency of $1.22 \%$, along with a $J_{\mathrm{sc}}$ of $7.33 \mathrm{~mA} \cdot \mathrm{cm}^{-2}$, a $V_{\text {oc }}$ of $0.33 \mathrm{~V}$ and a FF of $51 \%$. Despite being rather low compared to the performances of more conventional dyes, these results are quite consistent with previous reports on BODIPY sensitizers with absorption in the NIR region [36].

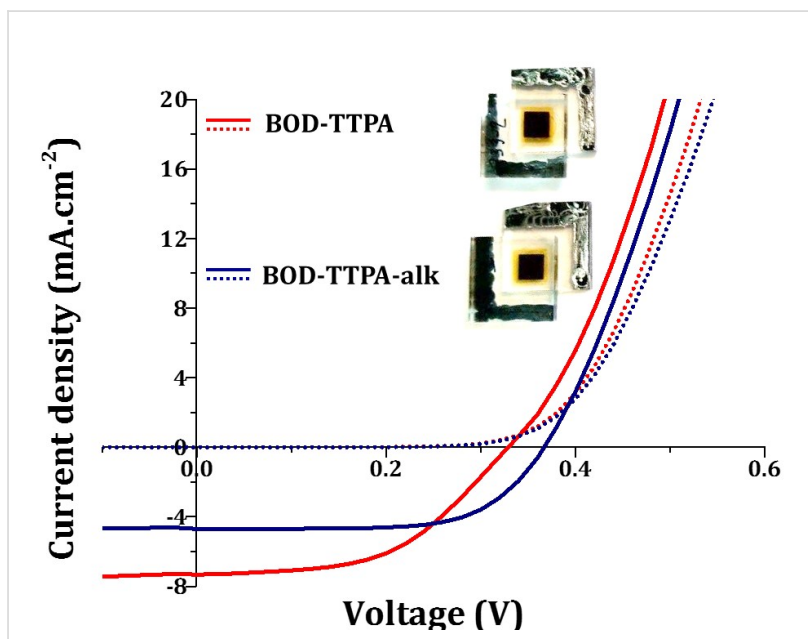

Figure 6: $J(V)$ curves of the best performing DSSCs devices sensitized with compounds BOD-TTPA-alk (blue traces) and BOD-TTPA (red traces) in dark (dashed lines) and under AM1.5G conditions (solid lines). Light source: $\mathrm{AM} 1.5 \mathrm{G}$ at $100 \mathrm{~mW} \cdot \mathrm{cm}^{-2}$, electrolyte composition: $0.5 \mathrm{M}$ of BMII, $0.03 \mathrm{M} \mathrm{of} \mathrm{I}_{2}, 0.5 \mathrm{M}$ of Lil, $0.1 \mathrm{M}$ of guanidinium thiocyanate in a mixture of acetonitrile and 3-methoxyproprionitrile (85:15, $\mathrm{v} / \mathrm{v}$ ), electrodes: $12 \mu \mathrm{m}$ mesoporous anatase $\mathrm{TiO}_{2}+4 \mu \mathrm{m} \mathrm{TiO}_{2}$ scattering layer, dyeing bath: $[$ Dye $]=0.2 \mathrm{mM},[\mathrm{CDCA}]=2 \mathrm{mM}$ in $\mathrm{CHCl}_{3} /$ EtOH 1:1 (v/v)).

First, comparing the photovoltaic behavior of the two dyes one should note that the $J_{\mathrm{sc}}$ delivered by the solar cells are rather different $\left(4.70 \mathrm{~mA} \cdot \mathrm{cm}^{-2}\right.$ for BOD-TTPA-alk versus $7.33 \mathrm{~mA} \cdot \mathrm{cm}^{-2}$ for BOD-TTPA). The higher $J_{\text {sc }}$ obtained with BOD-TTPA can be explained with the broader and more intense absorption in the NIR range once grafted on $\mathrm{TiO}_{2}$ compared to its alkylated counterpart. Second, one can notice that the $V_{\text {oc }}$ and FF recorded for devices sensitized with BODTTPA-alk are slightly higher compared to the ones prepared

Table 2: Photovoltaic parameters of compounds BOD-TTPA-alk and BOD-TTPA (light source: AM1.5G at $100 \mathrm{~mW} \cdot \mathrm{cm}^{-2}$, electrolyte composition: $0.5 \mathrm{M}$ of BMII, $0.03 \mathrm{M}$ of I $_{2}, 0.5 \mathrm{M}$ of Lil, $0.1 \mathrm{M}$ of guanidinium thiocyanate in a mixture of acetonitrile and 3-methoxyproprionitrile (85:15, v/v), electrodes: $12 \mu \mathrm{m}$ mesoporous anatase $\mathrm{TiO}_{2},+4 \mu \mathrm{m} \mathrm{TiO} 2$ scattering layer, dyeing bath: [Dye] $=0.2 \mathrm{mM},[\mathrm{CDCA}]=2 \mathrm{mM}$ in CHCl $\left.3 / \mathrm{EtOH} 1: 1, \mathrm{v} / \mathrm{v}\right)$. Highest value and mean values over three measurements in parenthesis.

\begin{tabular}{lllll} 
Dye & $J_{\mathrm{sc}}\left(\mathrm{mA} \cdot \mathrm{cm}^{-2}\right)$ & $V_{\mathrm{oc}}(\mathrm{V})$ & FF & PCE $(\%)$ \\
\hline BOD-TTPA-alk & $4.70(4.64)$ & $0.37(0.37)$ & $0.65(0.64)$ & $1.12(1.12)$ \\
BOD-TTPA & $7.33(7.10)$ & $0.33(0.33)$ & $0.51(0.50)$ & $1.22(1.20)$
\end{tabular}


out of BOD-TTPA. This could be explained by the presence of the alkyl chains on the TPA units that are known to prevent the redox mediator to interact with the $\mathrm{TiO}_{2}$ surface thus reducing the probability to observe a recombination process between the photo-injected electrons and the iodide.

To confirm that the main factor limiting the device performances is the position of the LUMO level of these dyes with respect to the $\mathrm{CB}$ of the oxide, we investigated the effect of ${ }^{\mathrm{t}} \mathrm{BP}$ content in the electrolyte. By adding ${ }^{\mathrm{t}} \mathrm{BP}$ in the electrolyte one can tune the electronic properties, i.e., the $\mathrm{CB}$ energy level position of $\mathrm{TiO}_{2}$ [31,37-39]. The effect is well-known, a negative dipole-related shift of the $\mathrm{TiO}_{2}$ Fermi level occurs by ${ }^{\mathrm{t}} \mathrm{BP}$ adsorption on the surface. As the LUMO levels of the dyes are estimated close to the CB Fermi level, the use of ${ }^{\mathrm{t}} \mathrm{BP}$ should lead to a drop of the $J_{\mathrm{sc}}$ because of the reduction of the driving force for the injection. Simultaneously a rise of the $V_{\mathrm{oc}}$ is expected. A shift of CB energy level toward the vacuum level (i.e., away from the redox potential of the electrolyte) results in a higher open-circuit voltage $\left(V_{\mathrm{oc}}\right)$. Indeed, in DSSCs the $V_{\mathrm{oc}}$ is determined by the quasi-Fermi-level of the metal oxide semi- conductor, which is correlated with its $\mathrm{CB}$ edge and electron density (see Figure 7).

Solar cells fabricated with various amount of ${ }^{\mathrm{t}} \mathrm{BP}$ in the electrolyte were investigated (see Table S1 in Supporting Information File 1). It appears from Figure 7 that increasing the concentration of ${ }^{\mathrm{t}} \mathrm{BP}$ implies, as expected, an increase of $V_{\mathrm{oc}}$, from $328 \mathrm{mV}$ to $460 \mathrm{mV}$ for BOD-TTPA-alk and from $360 \mathrm{mV}$ to $420 \mathrm{mV}$ for BOD-TTPA. On the other hand, the $J_{\mathrm{sc}}$ values for BOD-TTPA-alk and BOD-TTPA all decrease from 7.33 to $0.88 \mathrm{~mA} \cdot \mathrm{cm}^{-2}$ and from 4.70 to $0.41 \mathrm{~mA} \cdot \mathrm{cm}^{-2}$, respectively. This result unambiguously highlights that the shift of $\mathrm{TiO}_{2} \mathrm{CB}$ impedes the photo-injection of electrons [40]. This proves that the LUMO energy levels of the dyes BOD-TTPA-alk and BOD-TTPA are too close from the CB of the oxide. Despite a higher $V_{\mathrm{oc}}$, the loss of $J_{\mathrm{sc}}$ is responsible for the overall decrease of the power conversion efficiencies.

\section{Conclusion}

We have designed, synthesized and characterized two novel functional BODIPY-based dyes showing intense panchromatic a.

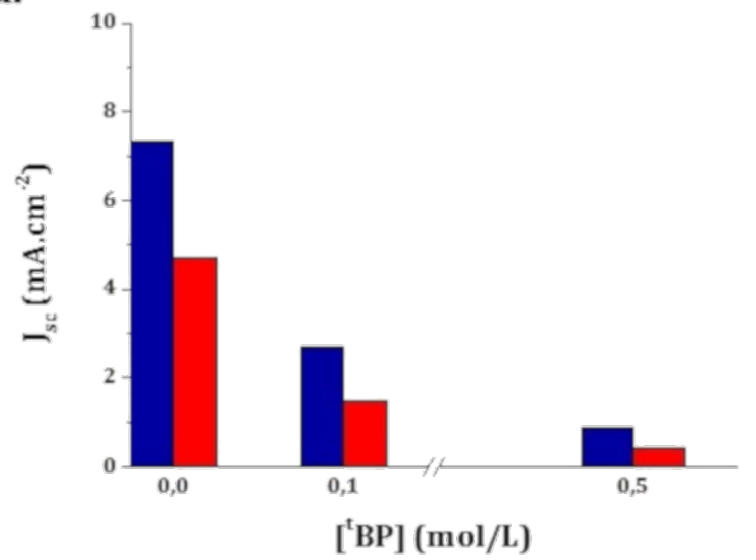

c.

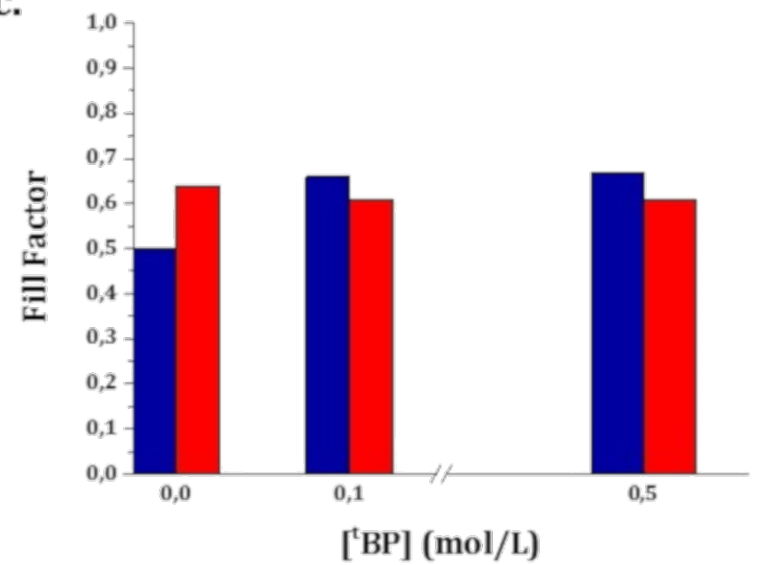

b.

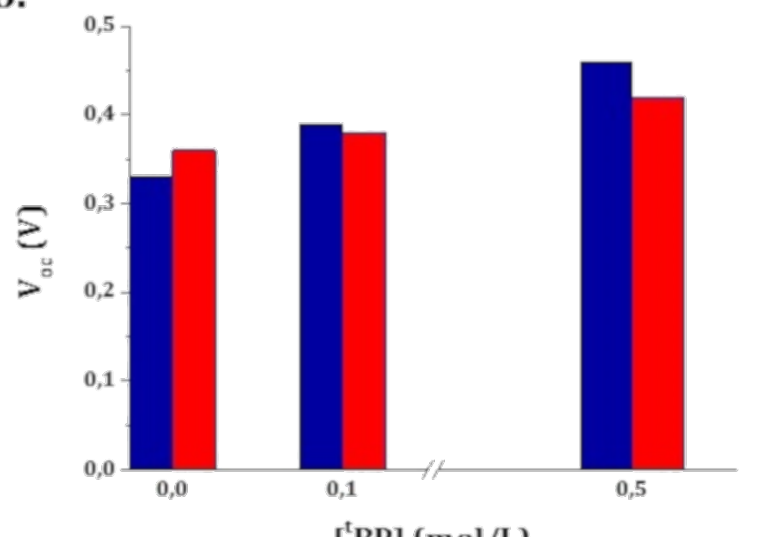

d.

[ $\left.{ }^{\mathrm{B}} \mathrm{BP}\right](\mathrm{mol} / \mathrm{L})$

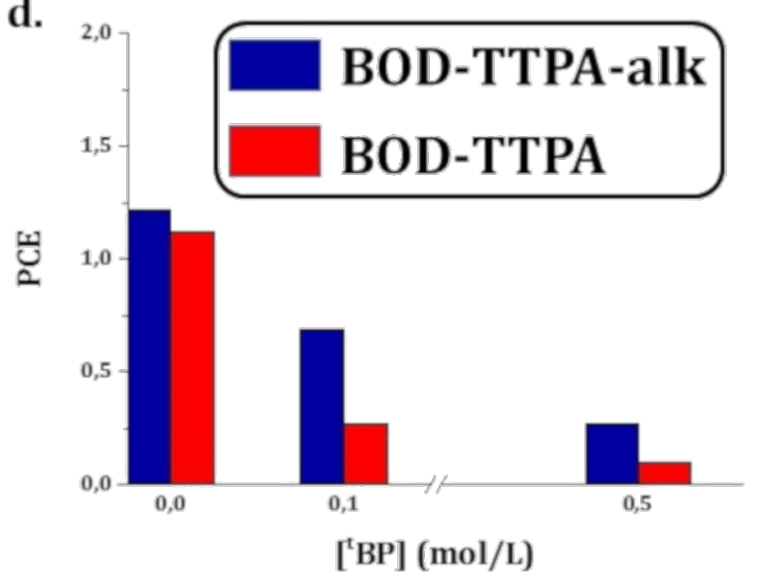

Figure 7: Photovoltaic parameters evolution with the increasing concentration of ${ }^{\mathrm{t}} \mathrm{BP}$ in the electrolyte. 
absorption that extends in the NIR region $\left(\varepsilon>2 \cdot 10^{4} \mathrm{M}^{-1} \cdot \mathrm{cm}^{-1}\right.$ from 300 to more than $800 \mathrm{~nm}$ ). The introduction of a cyanoacrylic anchoring function on these dyes allowed us to use them as photosensitizers of $\mathrm{TiO}_{2}$ mesoporous electrodes in a DSSC device configuration. We demonstrate PCEs of $1.12 \%$ and $1.22 \%$, respectively, for the dye bearing alkyl chains on the TPA unit and for the unsubstituted one. We identified that the limitation of their efficiency in solar cells originates from the unappropriated alignment of their LUMO energy levels with respect to the position of the $\mathrm{CB}$ of the metal oxide.

This work highlights that despite remarkable absorption properties, further structural optimization aiming at tuning the LUMO energy level position is necessary. This strategy is very likely to yield more efficient NIR sensitizers. Work following this conclusion is in progress.

\section{Supporting Information}

\section{Supporting Information File 1}

Experimental part and copies of NMR spectra.

[https://www.beilstein-journals.org/bjoc/content/ supplementary/1860-5397-15-169-S1.pdf]

\section{Acknowledgements}

The authors acknowledge financial support from the French Research Agency ANR (grants ANR ANR-14-OHRI-0003 ODYCE). DB is a FNRS Research Director.

\section{ORCID ${ }^{\circledR}$ iDs}

Quentin Huaulmé - https://orcid.org/0000-0003-2888-9887 Outi Vilhelmiina Kontkanen - https://orcid.org/0000-0002-2892-2141 David Beljonne - https://orcid.org/0000-0001-5082-9990 Gilles Ulrich - https://orcid.org/0000-0002-6980-6091 Renaud Demadrille - https://orcid.org/0000-0002-7455-5709

\section{References}

1. Kakiage, K.; Aoyama, Y.; Yano, T.; Oya, K.; Fujisawa, J.-i.; Hanaya, M. Chem. Commun. 2015, 51, 15894-15897. doi:10.1039/c5cc06759f

2. Mathew, S.; Yella, A.; Gao, P.; Humphry-Baker, R.; Curchod, B. F. E.; Ashari-Astani, N.; Tavernelli, I.; Rothlisberger, U.; Nazeeruddin, M. K.; Grätzel, M. Nat. Chem. 2014, 6, 242-247. doi:10.1038/nchem.1861

3. Yao, Z.; Wu, H.; Li, Y.; Wang, J.; Zhang, J.; Zhang, M.; Guo, Y.; Wang, P. Energy Environ. Sci. 2015, 8, 3192-3197. doi:10.1039/c5ee02822a

4. Joly, D.; Pellejà, L.; Narbey, S.; Oswald, F.; Chiron, J.; Clifford, J. N.; Palomares, E.; Demadrille, R. Sci. Rep. 2014, 4, 4033. doi:10.1038/srep04033

5. Wang, P.; Yang, L.; Wu, H.; Cao, Y.; Zhang, J.; Xu, N.; Chen, S.; Decoppet, J.-D.; Zakeeruddin, S. M.; Grätzel, M. Joule 2018, 2, 2145-2153. doi:10.1016/j.joule.2018.07.023
6. Fakharuddin, A.; Jose, R.; Brown, T. M.; Fabregat-Santiago, F.; Bisquert, J. Energy Environ. Sci. 2014, 7, 3952-3981. doi:10.1039/c4ee01724b

7. Aghazada, S.; Nazeeruddin, M. K. Inorganics 2018, 6, 52. doi:10.3390/inorganics6020052

8. Kubo, Y.; Eguchi, D.; Matsumoto, A.; Nishiyabu, R.; Yakushiji, H.; Shigaki, K.; Kaneko, M. J. Mater. Chem. A 2014, 2, 5204-5211. doi:10.1039/c3ta15340a

9. Cid, J.-J.; Yum, J.-H.; Jang, S.-R.; Nazeeruddin, M. K.; Martínez-Ferrero, E.; Palomares, E.; Ko, J.; Grätzel, M.; Torres, T. Angew. Chem., Int. Ed. 2007, 46, 8358-8362. doi:10.1002/anie.200703106

10. García-Iglesias, M.; Yum, J.-H.; Humphry-Baker, R.; Zakeeruddin, S. M.; Péchy, P.; Vázquez, P.; Palomares, E.; Grätzel, M.; Nazeeruddin, M. K.; Torres, T. Chem. Sci. 2011, 2, 1145-1150. doi:10.1039/c0sc00602e

11. Martín-Gomis, L.; Fernández-Lázaro, F.; Sastre-Santos, Á. J. Mater. Chem. A 2014, 2, 15672-15682. doi:10.1039/c4ta01894j

12. Ji, J.-M.; Zhou, H.; Kim, H. K. J. Mater. Chem. A 2018, 6, 14518-14545. doi:10.1039/c8ta02281j

13. Singh, S. P.; Gayathri, T. Eur. J. Org. Chem. 2014, 4689-4707. doi:10.1002/ejoc.201400093

14. Ulrich, G.; Ziessel, R.; Harriman, A. Angew. Chem., Int. Ed. 2008, 47, 1184-1201. doi:10.1002/anie.200702070

15. Zhang, D.; Martín, V.; García-Moreno, I.; Costela, A.; Pérez-Ojeda, M. E.; Xiao, Y. Phys. Chem. Chem. Phys. 2011, 13, 13026-13033. doi:10.1039/c1cp21038f

16. Cheng, M. H. Y.; Savoie, H.; Bryden, F.; Boyle, R. W. Photochem. Photobiol. Sci. 2017, 16, 1260-1267. doi:10.1039/c7pp00091j

17. Kowada, T.; Maeda, H.; Kikuchi, K. Chem. Soc. Rev. 2015, 44, 4953-4972. doi:10.1039/c5cs00030k

18. Huang, L.; Li, Z.; Zhao, Y.; Zhang, Y.; Wu, S.; Zhao, J.; Han, G. J. Am. Chem. Soc. 2016, 138, 14586-14591. doi:10.1021/jacs.6b05390

19. Bura, T.; Leclerc, N.; Fall, S.; Lévêque, P.; Heiser, T.; Retailleau, P.; Rihn, S.; Mirloup, A.; Ziessel, R. J. Am. Chem. Soc. 2012, 134, 17404-17407. doi:10.1021/ja3072513

20. Bessette, A.; Hanan, G. S. Chem. Soc. Rev. 2014, 43, 3342-3405. doi:10.1039/c3cs60411j

21. Klfout, H.; Stewart, A.; Elkhalifa, M.; He, H. ACS Appl. Mater. Interfaces 2017, 9, 39873-39889. doi:10.1021/acsami.7b07688

22. Qin, C.; Mirloup, A.; Leclerc, N.; Islam, A.; El-Shafei, A.; Han, L.; Ziessel, R. Adv. Energy Mater. 2014, 4, 1400085. doi:10.1002/aenm.201400085

23. Loudet, A.; Burgess, K. Chem. Rev. 2007, 107, 4891-4932. doi:10.1021/cr078381n

24. Aguiar, A.; Farinhas, J.; da Silva, W.; Ghica, M. E.; Brett, C. M. A.; Morgado, J.; Sobral, A. J. F. N. Dyes Pigm. 2019, 168, 103-110. doi:10.1016/j.dyepig.2019.04.031

25. Bulut, I.; Huaulmé, Q.; Mirloup, A.; Chávez, P.; Fall, S.; Hébraud, A.; Méry, S.; Heinrich, B.; Heiser, T.; Lévêque, P.; Leclerc, N. ChemSusChem 2017, 10, 1878-1882. doi:10.1002/cssc.201700465

26. Joly, D.; Pellejà, L.; Narbey, S.; Oswald, F.; Meyer, T.; Kervella, Y.; Maldivi, P.; Clifford, J. N.; Palomares, E.; Demadrille, R. Energy Environ. Sci. 2015, 8, 2010-2018. doi:10.1039/c5ee00444f

27. Zhang, F.; Wang, R.; Wang, Y.; Zhang, X.; Liu, B. Phys. Chem. Chem. Phys. 2019, 21, 6256-6264. doi:10.1039/c9cp00091g 
28. Mishra, A.; Fischer, M. K. R.; Bäuerle, P. Angew. Chem., Int. Ed. 2009, 48, 2474-2499. doi:10.1002/anie.200804709

29. Poirel, A.; De Nicola, A.; Retailleau, P.; Ziessel, R. J. Org. Chem. 2012, 77, 7512-7525. doi:10.1021/jo301300b

30. Bura, T.; Retailleau, P.; Ziessel, R. Angew. Chem., Int. Ed. 2010, 49, 6659-6663. doi:10.1002/anie.201003206

31. Hara, K.; Dan-oh, Y.; Kasada, C.; Ohga, Y.; Shinpo, A.; Suga, S.; Sayama, K.; Arakawa, H. Langmuir 2004, 20, 4205-4210. doi:10.1021/la0357615

32. Kulkarni, A. P.; Tonzola, C. J.; Babel, A.; Jenekhe, S. A. Chem. Mater. 2004, 16, 4556-4573. doi:10.1021/cm049473।

33. Goze, C.; Ulrich, G.; Mallon, L. J.; Allen, B. D.; Harriman, A.; Ziessel, R. J. Am. Chem. Soc. 2006, 128, 10231-10239. doi:10.1021/ja062405a

34. Grätzel, M. Acc. Chem. Res. 2009, 42, 1788-1798. doi:10.1021/ar900141y

35. Rühle, S.; Greenshtein, M.; Chen, S.-G.; Merson, A.; Pizem, H.; Sukenik, C. S.; Cahen, D.; Zaban, A. J. Phys. Chem. B 2005, 109, 18907-18913. doi:10.1021/jp0514123

36. Erten-Ela, S.; Yilmaz, M. D.; Icli, B.; Dede, Y.; Icli, S.; Akkaya, E. U. Org. Lett. 2008, 10, 3299-3302. doi:10.1021/ol8010612

37. Koops, S. E.; O'Regan, B. C.; Barnes, P. R. F.; Durrant, J. R. J. Am. Chem. Soc. 2009, 131, 4808-4818. doi:10.1021/ja8091278

38. Yu, Q.; Wang, Y.; Yi, Z.; Zu, N.; Zhang, J.; Zhang, M.; Wang, P. ACS Nano 2010, 4, 6032-6038. doi:10.1021/nn101384e

39. Nazeeruddin, M. K.; Kay, A.; Rodicio, I.; Humphry-Baker, R.; Mueller, E.; Liska, P.; Vlachopoulos, N.; Graetzel, M. J. Am. Chem. Soc. 1993, 115, 6382-6390. doi:10.1021/ja00067a063

40. Wu, J.; Lan, Z.; Lin, J.; Huang, M.; Huang, Y.; Fan, L.; Luo, G. Chem. Rev. 2015, 115, 2136-2173. doi:10.1021/cr400675m

\section{License and Terms}

This is an Open Access article under the terms of the Creative Commons Attribution License (http://creativecommons.org/licenses/by/4.0). Please note that the reuse, redistribution and reproduction in particular requires that the authors and source are credited.

The license is subject to the Beilstein Journal of Organic Chemistry terms and conditions:

(https://www.beilstein-journals.org/bjoc)

The definitive version of this article is the electronic one which can be found at: doi:10.3762/bjoc. 15.169 